\title{
Economic Resilience Through Community-Driven (Real Estate) Development in Amsterdam-Noord
}

\author{
Matthijs Bouw and Despo Thoma
}

\begin{abstract}
Shifts in the perception of risks and precedents of unsuccessful urban planning efforts in the twenty-first century highlight the conflicting nature of 'control' and 'flexibility' in modern urban practices. This essay argues that urban planning can be revisited today through the lens of the 'commons'. The notion of commons can be seen as the key to approach top-down and bottom-up initiatives in a systematic way. In this contribution, we argue that collective self-building in Amsterdam-Noord is a type of commons-based urban planning that occupies a unique territory in between state-led and market-led practices, and private efforts of urban development. By correlating the evolving definitions of the commons with the omnipresent dilemmas of urban planning, this essay intends to draw a link between the two, arguing for a more resilient form of city-making. We argue that commons-based urban planning offers a resilient alternative to the master plan, as one of its key strengths lies in the economic and social models it is based on. Finally, this essay attempts to examine the ways new technologies allow us today to revisit and reform the understanding of self-initiation and shared resources in urban environments.
\end{abstract}

Keywords Economic resilience $\cdot$ Commons $\cdot$ Community-driven planning Public-private partnerships $\cdot$ Urban planning $\cdot$ Urbanism $\cdot$ Resilient design Bottom-up $\cdot$ Top-down $\cdot$ City-making $\cdot$ One Architecture

In the fall of 2015, on an improvised camping ground in Amsterdam-Noord, more than a hundred caravans and tents were set up, and their owners were willing to camp out for more than three weeks in order to sign up for a plot of land in the area, called Buiksloterham, on which they could build their own house or with a group of like-minded people, a small apartment building. While in line, the campers talked enthusiastically with each other about their individual dreams and speculated about the communal efforts that might be undertaken to lower costs or to increase

\footnotetext{
M. Bouw · D. Thoma ( $\varangle)$

One Architecture \& Urbanism, 35 E Broadway \#5C, New York, NY 10002, USA

e-mail: thoma@onearchitecture.nl

M. Bouw

e-mail: bouw@onearchitecture.nl

(C) The Author(s) 2019

M. de Lange and M. de Waal (eds.), The Hackable City,

https://doi.org/10.1007/978-981-13-2694-3_6
} 
sustainability. Quite a few on the camping site were local architects who had, from 2008, during the prolonged real estate crisis that was just ending, been leading small development efforts in what had always been an unloved industrial area. They had built houses for themselves and for friends, nicely lined up in one unorthodox street, brought groups together and designed small apartment buildings for them, and experimented with soil remediation, sustainability, and circular economies (Reimerink 2016). These pioneers had made Buiksloterham an exemplary case of urban resilience in face of a real estate crisis.

In this contribution, we argue that collective self-building in Amsterdam-Noord is a type of commons-based urban planning that occupies a unique territory in between state-led and market-led practices and private efforts of urban development. We argue that commons-based urban planning offers a resilient alternative to the master plan, as one of its key strengths lies in the economic and social models it is based on. Our analysis of this phenomenon in this chapter will start with framing traditional urban practices in opposition to resilient systems, address the role of social systems and shared resources (the commons) therein and work toward a generally applicable model for such a commons-based economically resilient urban planning that utilizes new technologies and digital tools.

Over the course of the last decades, urban planning has been formed by the need to accommodate pressures for development while avoiding chaotic accumulations and conditions that had led to the rise of the 'master plan', often considered as a blueprint for the future city or neighborhood. In light of establishing basic rules for accessibility and sanitation, master plans have evolved into hyper-detailed recipes for city development that seem to operate under the understanding that social systems are predictable, simple, and controllable (Moroni 2010). As such, planning strategies include a set of concrete and directional rules that often lack the flexibility and adaptability more organic and resilient systems appear to have. To counterbalance the rigidity of the master plan, self-organized activities are nowadays welcomed by planners (Savini et al. 2015) for their ability to engage with a variety of uses, scales, and audiences, allowing room for creativity and innovation. However, these bottomup city-making initiatives are still understood as activities of individuals that need to be controlled by the 'master' city-maker, and by themselves are not enough to foster resilient urban growth.

We would like to define resilience here as 'the ability to deal with shocks and stresses, and the ability to transform itself within critical thresholds' (Martin-Breen and Anderies 2011). Urban development models that are based on the idea of the master plan often fail to account for potential shocks and stresses and exacerbate initial triggers due to their inherent rigidness in scale and time. During periods of economic distress, large urban projects are often halted or permanently cancelled in the face of an increased risk, leading to a decline in urban development. When projects have halted, we can observe the rise of more resilient social and economic systems, indicative of new modes of urban thinking. In a 'risk society' (Beck 2006), an antidote of the master plan can be found in the field of resilience, which arises as a focal point and an indicator of systematic, iterative urban thinking. In times where risk is omnipresent in some capacity and failure starts to be embraced as 
a possible outcome, engaging the ever-changing nature of systems and allowing flexibility become a new direction for urban planning.

The district of Buiksloterham, in Amsterdam-Noord, can be seen as exemplary for this new approach to planning. In a development process driven mostly by individuals and groups of individuals, rather than professional developers, simple financial models fostered bottom-up urban development and have pointed to a new more resilient mode of city-making. After the 2008 economic crash, it became clear that the Dutch real estate sector was not very resilient. Bloated and uncompetitive after decades of ever-increasing liquidity because of tax policies and easily available mortgages, housing prices collapsed (Scanlon and Elsinga 2014). This led to an extended economic downturn. Projects were cancelled, and no new projects were undertaken, leading to a radical decline of the construction industry (CBS 2015) and the virtual disappearance to the real estate developer (Hentenaar 2015), who was unmasked to be not much more than a 'mister ten percent' in the real estate value chain.

In Buiksloterham, as in a few other areas in the country, such as Almere (Feary 2015) and Deventer (Welovethecity.eu 2015), citizen-driven real estate development proved to be an alternative economic model. Unlike the traditional development initiated by cities, developers, and housing corporations, in which integral and ambitious plans were proposed (only to be either cancelled or value engineered at a later stage), this development was based on simple urban plans in which individuals, or groups of individuals, could build their own houses or apartment buildings. The reason this type of development continued on pace during the prolonged real estate crisis was perhaps because of the simplicity of the development model, and as a result of the simple financing model, which bypassed to a large extent, project finance loans, risk management committees, credit board reviews, and other manifestations of financialization. We earlier described this as 'real people building real houses for their families with real money', sometimes with help from family or from the local architects (Hill 2016).

While the traditional real estate sector proved largely unable to deal with the shock of the crisis, this more organic mode of development has proven to be much more resilient. In fact, it can even be argued that this way of development has-what the former Rockefeller Foundation president Judith Rodin calls - a clear 'resilience dividend', in which communities become stronger, more prosperous and more connected in the process of building resilience (Resiliencedividend.org 2016). The neighborhoods are much more diverse than those that have been developed by 'professionals' with regard to the variation of housing types. A study assessing the first self-developed apartment buildings in Buiksloterham demonstrated that for instance, the quality of the architecture is higher, with higher quality materials, higher ceilings, and more outside space, in part because a large part of the total investment sum is actually spent 'in stone'. Also, the energetic performance of the buildings is better, probably because a period for earning back an investment of more than 10 years is still considered worthwhile. The projects were innovative in their use of new technology to achieve this and had floor plans that are more flexible. The communities have organized themselves around the 'circular economy', with the reuse of local resources, understanding that natural and cultural resources can be shared and be collectively 
owned. People felt more involved in the development process and in the community, which results in more loved neighborhoods (Van de Klundert 2017).

Many of the characteristics of the Buiksloterham brownfield transformation in Amsterdam-Noord, which is the most prominent of these organic developments in the Netherlands, can be understood in terms of resilience. Resilience proposes to engage complex systems, such as a city, or the city-making process, through multifunctionality, redundancy and modularization, embracing (bio and social) diversity, and by connecting multi-scale networks in such a way that the systems becomes adaptive (Ahern 2011). Adaptability in systems implies a responsive and observant mode of governance. Understanding that rules of governance for shared urban resources appear to be more flexible when they arise as a collective effort from the community allows innovation in the way urban development is enabled and controlled. Although it has become priority for urban planners to include methods of co-creation with the community, the tension between the need to establish future goals and the necessity to allow physical and cultural flexibility remains in most planning processes (Savini et al. 2015). In Buiksloterham, planning methods indicate a shift from a set of permanent and fixed rules to a process that fosters and advocates for the creation of community-tailored guidelines and appreciates the value of shared natural and cultural resources.

The notion of the commons has resurfaced as a lens to understand social, economic, and political developments of this century. The commons were addressed in the last century by Garrett Hardin in 1968 in his paper the 'Tragedy of the Commons' (Hardin 1968). Commons were defined as social systems in which resources are shared by a community of users and producers. This community also defines the rules of production, distribution, and circulation through democratic and horizontal forms of governance. Hardin believed that individuals inevitably end up overexploiting and degrading common resources. Based on this paradigm, it is no surprise that policy makers have since interpreted individuals and their interests as potential threats to the resources that communities share. The conflicting interests between the individual and the collective have led to the establishment of new rules for social and economic behavior during the past century, to allow private growth and mitigate its collective effects. The commons, and more specifically their relationship with the individual, are influencing social and economic activities (De Angelis and Harvie 2014), and as such are essential in urban transformations.

Elinor Ostrom in her study 'Governing the Commons' (Ostrom 1990) attempts to refute Hardin's basic assumption that individuals are incapable of self-governing their resources. She puts forward the idea that current private and governmental modes of regulating are based on generalizations and as such are blind to the capabilities of individuals. Ostrom argues that communities can create their own institutions, rules, and enforcement mechanisms which ensure the sustainable use of their resources. As she states, if certain conditions are met, there is no need for top-down regulations. Ostrom summarized the conditions in the form of eight core design principles: (1) clearly defined boundaries; (2) proportional equivalence between benefits and costs; (3) collective-choice arrangements; (4) monitoring; (5) graduated sanctions; (6) fast and fair conflict resolution; (7) local autonomy; (8) appropriate relations with other 
tiers of rule-making authority (polycentric governance) (Ostrom 1990, 90). Understanding the co-relation between the sense of collectiveness and the empowerment of the individual becomes a critical viewpoint of urban thinking. It is at this point where Ostrom's basic principles can be revisited and reiterated to be applicable to urban commons (Foster 2017) in order to resolve the tension between 'governing urban shared resources' and 'allowing flexible urban transformation'. Contra Hardin and in line with Ostrom, we argue that self-organized collective commons-based self-building may indeed constitute a very resilient form of urban planning.

The scale of development in Buiksloterham is small. Each project is principally driven by each own logic. There is little need for coordination. When one project stalls, the development of the neighborhood can just continue. There is a focus on flexibility in program and space, especially since the building groups realize that group processes are inherently dynamic. And, through this piecemeal development, builders learn from each other and connect to each other to see if things can be shared, such as a heat pump or the drilling of the piles. As such, the social fabric of the future community continues to strengthen, knowledge and resources are shared, and common values are adapted. The self-builder who constructs his houses from building material auctioned off from bankrupt contractors has much in common with the young architects who experiment with cleaning up contaminated soil with the use of plants (Reimerink 2016).

Out of these initially individual experimental projects slowly an ethos or a culture has emerged, in which early collaborations solidified themselves over time, and institutional actors became part of this ecology. A manifesto for a 'Circular Buiksloterham' was signed by some 20 different stakeholders, from self-builders to housing corporations to utilities. The architects who have worked with the 'building groups' jointly promote the area and themselves under the title 'Beleef Buiksloterham', Experience Buiksloterham (Buiksloterham.nl 2015). And One Architecture has teamed with the research group The Mobile City and three universities (University of Amsterdam, the Amsterdam University of Applied Sciences, and Utrecht University) in an action-based research project 'Buiksloterham Hackable City', with the goal of exploring how digital technology can facilitate commons-based collective self-building as a kind of resilient hacking of the city, and how this becomes more accessible for individuals and collectives (Savini and Dembski 2016).

Slowly, the institutional actors started to develop projects with a distinctly Buiksloterham vibe. Housing corporation 'De Alliantie' is developing 'Cityplot' as a diverse, mixed-use area with room for self-development and a high, circular ambition (Cityplot-buiksloterham.nl 2015). Waternet, the water utility company, is working on a 'biorefinery', a decentralized waste management system (Waternet.nl 2017). And the architects have united in order to explore collectively if the lessons learned in Buiksloterham can be repeated at a larger scale, with potential future Buiksloterhammers, in a way that value can be re-invested locally.

If building resilience necessitates adaptive planning and design, the continuous prototyping of solutions makes city-making at Buiksloterham an iterative process. And while there is no master plan and no master planner, local designers such as Studioninedots, Delva Landscape, and One Architecture 'lead from behind' by orga- 
nizing the collective efforts such that new prototypes and projects more advanced and often at a larger scale than earlier iterations, can be developed. Taken together, these different efforts combine into a networked model of area development, in which government is not so much leading the process but merely an actor in it.

One Architecture, for example, was first involved as architects and codevelopers with a few building groups in Buiksloterham, which are now also Waternet's consultant on the biorefinery. In addition, the 'Hackable City' (Thehackablecity.nl 2017) research project (that they are part of) explores and utilizes digital tools in order to organize individual actors in learning collectives, and to advocate in favor of institutional change through collective action. Subprojects of the 'Hackable City' include a system for sharing information and experiences by the individual self-builders (such that the valuable knowledge they develop in the process is a common resource and can be used by others), a 'water game' that generates community awareness of and solutions for water issues, a decision-making system that defines when to approach infrastructure development decentrally, and when centrally, a monitoring system for the performance of the built environment such that the metrics can be used to argue for institutional change, and a version of 'Play the City', a 'serious game' for engaging the various stakeholders. While developing tools for city-making and with that researching the possibility for 'hackable' city-making processes, the project also makes a strong case for Buiksloterham as a continuous 'living lab', in which 'lessons learned' can be applied to future projects, and knowledge is appreciated as a common resource that, contrary to other common resources, is not scare and actually profits from being abundantly circulated. These learning processes help strengthen this resilient way of city-making.

In that sense, the prolonged real estate crisis, in which Amsterdam was bypassed by global capital and in which the traditional actors have been passive or absent, has given rise to a unique new way of city-making; Buiksloterham has had enough time to develop a building culture and community that now makes it one of the most attractive and desirable Amsterdam neighborhoods.

Now that the local real estate market is bouncing back rapidly, and global real estate capital has landed in Amsterdam too, the Buiksloterhammers have a huge challenge ahead. The Amsterdam municipality is inclined to ride the wave and go back to the ways of old, selling the area in large plots to big developers and, in the process, reducing sustainability requirements, with the argument that houses need to be build fast to follow demand (and with the added benefit of generating revenue for the municipality) (Vastgoedmarkt.nl 2017). Now the local actors have to show that the organic way of development can adapt to booms, claim their continuous role in Buiksloterham, and argue that their way of 'hackable', 'circular', and 'commonsbased' city-making is an essential ingredient of a resilient city because it brings more resilience dividends than Amsterdam's strategy of filling their coffers in order to withstand another crisis.

If Buiksloterhammers manage this new reality and find ways to establish their way of city-making, it will not only provide Amsterdam with the instruments to deal with the inevitable bust, it will also establish a powerful way of city-making that can not only deal with real estate cycles, but can be especially useful for those mid-size 
cities or real estate markets that are bypassed by global capital in the first place. It is often there that the activation of local (social) capital through 'hackable' city-making is crucial to liveability and economic development.

Through the example of Buiksloterham, economic and social resilience escapes the level of abstract ideas and transforms into an implementable set of guidelines to allow commons to revive in a new form in the twenty-first century. The role of new technologies in the formation and long-term sustainability of the neighborhood can be seen as evidence of the potential of new platforms of communication. The necessity to foster the growth of small local investments and to empower individuals within their communities arises as a prominent aspect of urban thinking. Buiksloterhammers can be seen as potential citizens of the future city, able to invest and help sustain social and economic growth in their neighborhoods, and by extent, allowing urban planning to move from a totalitarian practice to a practice of enabling and fostering in search of the commons.

\section{References}

Ahern, Jack F. 2011. From fail-safe to safe-to-fail: Sustainability and resilience in the new urban world. Landscape architecture \& regional planning studio and student research and creative activity 8. ScholarWorks@UMass Amherst. https://scholarworks.umass.edu/cgi/viewcontent. cgi?article=1008\&context=larp_grad_research. Accessed 25 July 2018.

Beck, Ulrich. 2006. Living in the world risk society: A hobhouse memorial public lecture given on Wednesday 15 February 2006 at the London School of Economics. Economy and Society 35 (3): 329-345.

Buiksloterham.nl. 2015. Buiksloterham. http://buiksloterham.nl/. Accessed 18 Feb 2017.

CBS. 2015. Bouw beleeft in 2015 hoogste omzetgroei sinds crisis. https://www.cbs.nl/nl-nl/nieuws/ 2016/07/bouw-beleeft-in-2015-hoogste-omzetgroei-sinds-crisis. Accessed 8 Jan 2017.

Cityplot-buiksloterham.nl. 2015. Cityplot Buiksloterham. http://www.cityplot-buiksloterham.nl/. Accessed 18 Feb 2017.

De Angelis, Massimo, and David Harvie. 2014. The commons. In The routledge companion to alternative organizations, ed. Martin Parker, George Edward Cheney, Valerie Fournier, and Chris Land, 280-294. Abington: Routledge.

Feary, Thomas. 2015. Inside Almere: The Dutch city that's pioneering alternative housing. The guardian. https://www.theguardian.com/housing-network/2015/dec/15/almere-dutch-cityalternative-housing-custom-build. Accessed 10 Feb 2016.

Foster, Sheila. 2017. Ostrom in the city: Design principles for the urban commons. The nature of cities. https://www.thenatureofcities.com/2017/08/20/ostrom-city-design-principlesurban-commons/. Accessed 22 Aug 2017.

Hardin, Garrett. 1968. The tragedy of the commons. Science 162 (3859): 1243-1248.

Hentenaar, Rogier. 2015. Wat waren de grootste faillissementen in het vastgoed? Vastgoed Journaal. https://vastgoedjournaal.nl/news/18339/57/Wat-waren-de-grootste-faillissementen-in-hetvast. Accessed 8 Jan 2017.

Hill, Dan. 2016. The social and the democratic, in the social-democratic city. Medium. https://medium.com/dark-matter-and-trojan-horses/the-social-and-the-democratic-in-socialdemocratic-european-cities-31e0bc169b0b. Accessed 8 Jan 2017.

Martin-Breen, Patrick, and J. Marty Anderies. 2011. The Bellagio initiative resilience: A literature review. The Rockefeller Foundation. 
Moroni, Stefano. 2010. Rethinking the theory and practice of land-use regulation: Towards nomocracy. Planning Theory 9 (2): 137-155.

Ostrom, Elinor. 1990. Governing the commons: The evolution of institutions for collective action. Cambridge: Cambridge University Press.

Reimerink, Letty. 2016. How Amsterdam turned a polluted industrial site into its most interesting neighborhood. CityLab. https://www.citylab.com/design/2016/03/how-a-polluted-industrialsite-became-amsterdams-most-interesting-neighborhood/474618/. Accessed 27 July 2018.

Resiliencedividend.org. 2016. Being strong in a world where things go wrong: A description of Judith Rodin' book 'Resilience Dividend.' http://resiliencedividend.org. Accessed 8 Jan 2017.

Savini, Federico, and Sebastian Dembski. 2016. Manufacturing the creative city: Symbols and politics of Amsterdam North. Cities 55: 139-147.

Savini, Federico, Stan Majoor, and Willem Salet. 2015. Dilemmas of planning: Intervention, regulation, and investment. Planning Theory 14 (3): 296-315.

Scanlon, Kathleen, and Marja Elsinga. 2014. Policy changes affecting housing and mortgage markets: How governments in the UK and the Netherlands responded to the GFC. Journal of Housing and the Built Environment 29 (2): 335-360.

Thehackablecity.nl. 2017. The hackable city. www.thehackablecity.nl. Accessed 8 Jan 2017.

van de Klundert, Froukje. 2017. Collective vs. traditional: What are the lessons learned of cooperative development on plot 21 in Buiksloterham? The hackable city. http://thehackablecity.nl/2017/01/30/01-february-2017-collectief-vs-traditioneel-wat-zijnde-lessen-van-cooperatieve-ontwikkeling-op-kavel-21-in-buiksloterham. Accessed 10 Feb 2017.

Vastgoedmarkt.nl. 2017. Vereveningsfonds Amsterdam stijgt naar 356 miljoen. http://www. vastgoedmarkt.nl/financieel/nieuws/2017/4/vereveningsfonds-amsterdam-stijgt-naar-356miljoen-101120418. Accessed 8 July 2017.

Waternet.nl. 2017. Samenwerken. http://www.innovatie.waternet.nl/project/proeftuin-circulairbuiksloterham/?meer=true. Accessed $18 \mathrm{Feb} 2017$.

Welovethecity.eu. 2015. Habour quarter deventer. http://www.welovethecity.eu/en/portfolio/ habour-quarter-deventer. Accessed 10 Feb 2016.

Matthijs Bouw is a Dutch architect and founder of One Architecture (est 1995), which focuses on urban design and resilient architecture. He currently serves as the Rockefeller Urban Resilience Fellow for Penn Design at the University of Pennsylvania. Mr. Bouw has been a guest professor at, a.o., TU Delft, Berlage Institute, TU Graz, University of Kentucky College of Design and Sci-Arc, and was professor I.V. of 'Gebaeudelehre und Grundlagen des Entwerfens' at the RWTH Aachen.

A leading voice on Resilient Design, he has published several dozen papers and given numerous talks to both students and professionals on incorporating resiliency into design practice. Bouw's own practice is known for its unique approach in which programmatic, financial, technical and organizational issues are addressed, communicated and resolved through design. Bouw has been a pioneer in the use of design as a tool for collaboration, for instance through the development of 'Design Studios' as an instrument to support the Netherlands' Ministry of Infrastructure and the Environment with its long-term planning, and in community-development projects.

Despo Thoma is a Cypriot urban designer at One Architecture \& Urbanism (ONE) in New York, and a registered architect. She holds a bachelor's and master's degree in Architecture from the National Technical University of Athens and a M.Sc. in Architecture and Urban Design from Columbia University as a Fulbright Fellow. At Columbia, Despo was awarded the GSAPP Prize for Excellence in Urban Design for the most outstanding body of work. Despo has spent time as faculty member at Columbia GSAPP and NJIT, as Design Research Fellow at the Institute of Public Architecture, and as guest critic at Parson's New School of Design, City College of New York, and NYIT. At ONE, Despo is acting as project manager and lead urban planner for the Resilient By Design Bay Area Challenge and Lead Urban Designer for the Water as Leverage Program in 
Semarang, Indonesia. Thoma has contributed to RPA's Fourth Regional Plan: The Triboro Corridor, and the two coastal resiliency projects that came out of the Rebuild By Design winning proposal 'BIG U' that reshape the future coastline of Lower Manhattan. Despo's personal research focuses on congested territories and conflict resolution, and embodies her belief in moving away from the notion of design as a tool for object-production and toward a more collaborative processoriented use of design.

Open Access This chapter is licensed under the terms of the Creative Commons Attribution 4.0 International License (http://creativecommons.org/licenses/by/4.0/), which permits use, sharing, adaptation, distribution and reproduction in any medium or format, as long as you give appropriate credit to the original author(s) and the source, provide a link to the Creative Commons license and indicate if changes were made.

The images or other third party material in this chapter are included in the chapter's Creative Commons license, unless indicated otherwise in a credit line to the material. If material is not included in the chapter's Creative Commons license and your intended use is not permitted by statutory regulation or exceeds the permitted use, you will need to obtain permission directly from the copyright holder. 